P-ISSN 2580 - 7781

E-ISSN $2615-3238$

\title{
MOTIVASI GURU-GURU PAUD DALAM MELANJUTKAN BELAJAR/PERKULIAHAN PADA S1 PROGRAM STUDI PENDIDIKAN GURU PAUD DI KABUPATEN KEBUMEN
}

\section{MOTIVATION OF PAUD TEACHERS IN CONTINUING LEARNING/LECTURE IN SI EDUCATION STUDY PROGRAM FOR PAUD TEACHERS IN KEBUMEN REGENCY}

\author{
Alek Andika ${ }^{1}$, Habib Hambali ${ }^{2}$ \\ ${ }^{1}$ Pendidikan Bahasa Inggris, Fakultas Keguruan dan Ilmu Pendidikan \\ Universitas Ma'arif Nahdlatul Ulama Kebumen \\ ${ }^{2}$ Pendidikan Anak Usia Dini, Fakultas Keguruan dan Ilmu Pendidikan \\ Universitas Ma'arif Nahdlatul Ulama Kebumen \\ ${ }^{1}$ Email: mr12011989@gmail.com
}

\begin{abstract}
ABSTRAK
Penelitian ini bertujuan untuk: 1. Mendapatkan gambaran/diskripsi motivasi dan perilaku para guru PAUD yang sudah mengajar dan mau melanjutkan kuliah S1 pada Program PAUD; 2. Mengetahui gambaran secara umum mahasiswa Prodi PAUD; 3. Menggali informasi terkait hubungan antara motivasi kuliah guru PAUD dengan kendala/tanggung jawab mereka menjadi seorang mahasiswa. Penelitian ini dilakukan pada guru PAUD yang sedang melanjutkan studi S1 PAUD di Kabupaten Kebumen. Sedangkan metode penelitian yang digunakan adalah kualitatif dengan melakukan pengumpulan data (collecting data) yang diperoleh dari Dinas Pendidikan Kabupaten Kebumen tahun 2020 melalui 3 cara yaitu wawancara, observasi dan studi dokumentasi. Selanjutnya peneliti beserta Tim melakukan analisis data penelitian yang telah diperoleh melalui 3 langkah yaitu (reduksi, penyajian data dan penarikan kesimpulan). Setelah peneliti melakukan langkah-langkah penelitian diatas, peneliti menemukan kesimpulan yang menunjukkan dominasi motivasi guru untuk melanjutkan belajar/kuliah adalah menambah wawasan keilmuan baik akademik maupun non akademik. Motivasi selanjutnya adanya harapan peningkatan kesejahteraan setelah mendapatkan gelar sarjana. Dalam hal ini bahwa secara regulasi terkait guru PAUD baik regulasi yang berasal dari PEMDA ataupun Kementerian Pendidikan bahwa untuk mendapatkan kesra (kesejahteraan) dan sertifikasi guru maka harus berpendidikan minimal S1 sedangkan sebagian besar guru PAUD di Kebumen masih berpendidikan SLTA sederajat.
\end{abstract}

Kata kunci: Motivasi, Belajar, Keilmuan, Guru PAUD

\section{ABSTRACT}

This study aims to: 1. Obtain a description / description of the motivation and behavior of early childhood (PAUD) teachers who have taught and want to continue their undergraduate studies in the PAUD program. 2. Knowing an overview of PAUD Study Program students. 3. Exploring information related to the relationship between preschool teacher motivation and their constraints / responsibilities as students. This research was conducted on early childhood teachers who continued their undergraduate studies in early childhood education in Kebumen Regency. While the research method used is qualitative by collecting data obtained from the Kebumen Regency Education Office in 2020 through 3 ways, namely interviews, observation and documentation study. 
P-ISSN 2580 - 7781

E-ISSN $2615-3238$

Furthermore, the researcher and the team analyzed the research data that had been obtained through 3 stages, namely (reduction, data display and conclusion). After the researchers carried out the research steps above, the researchers found conclusions that indicate the dominance of the teacher's motivation to continue studying/lecture is to add scientific insight both academic and non-academic. The next motivation is the hope of increasing welfare after getting a bachelor's degree. In this case, the regulations related to PAUD teachers, both regulations originating from the Regional Government or the Ministry of Education, state that in order to obtain welfare and teacher certification, a minimum of S1 education is required, while the majority of PAUD teachers in Kebumen still have an equivalent high school education.

Keywords: Motivation, Learning, Science, Early childhood teachers.

\section{PENDAHULUAN}

Pada tahun 2045 Indonesia akan genap berumur 100 tahun, dimana pemerintah mempersiapkan Indonesia menuju generasi emas. Hal ini sejatinya dapat menjadi momentum yang sangat penting bagi bangsa Indonesia terlebih pada tahun tersebut Indonesia dalam posisi bonus demografi. Bonus demografi nantinya negara Indonesia memiliki jumlah penduduk dalam usia produktif (15-64 tahun) sekitar 70\%. Salah satu aspek vital yang harus dipersiapkan adalah pendidikan. Kualitas pendidikan semakin tahun semakin tinggi. Hal ini dikarenakan program pemerintah dalam meningkatkan kualitas pendidikan di Indonesia. Dimana salah satunya adalah kualifikasi pendidikan guru/tenaga pendidik. Guru kini harus memiliki strata pendidikan minimal S1, baik pendidikan yang ada di jenjang non formal, informal terlebih jenjang formal.

Kualitas siswa sebagai generasi bangsa tergantung pada kualitas guru yang menjadi tolak ukur kualitas pendidikan di Indonesia. Selanjutnya penggalakan pendidikan anak usia dini oleh pemerintah juga sangat gencar. Mengacu pada Undang-undang No 20 Tahun 2003, pasal 1 butir 14 tentang Sistem Pendidikan Nasional, Pendidikan Anak Usia Dini (PAUD) adalah suatu upaya pembinaan yang ditujukan bagi anak sejak lahir sampai dengan usia (6) enam tahun yang dilakukan melalui pemberian rangsangan pendidikan untuk membantu pertumbuhan dan perkembangan jasmani dan rohani agar anak memiliki kesiapan dalam memasuki pendidikan lebih lanjut.

Penyampaian ilmu "transfer knowledge" oleh guru kepada siswa/peserta didik menjadi proses yang sangat penting. Terlebih pada usia dini merupakan 
"golden age" usia emas dimana daya tangkap siswa sangatlah kuat. Dalam hal ini sangat disayangkan sekali bahwa mendasar pada data statistik, sebagian besar guru PAUD (Pendidikan Anak Usia Dini) belum berijazah S1 dan meskipun sebagian yang sudah berijazah S1, bukanlah S1 linier Pendidikan Anak Usia Dini. Program Studi Pendidikan Anak Usia Dini (PG-PAUD) merupakan Program Studi yang memiliki tujuan untuk menghasilkan pendidik Anak Usia Dini yang profesional dan yang islami, menghasilkan pendidik Anak Usia Dini (AUD) yang mampu memberikan layanan kepakaran kepada masyarakat, menghasilkan SDM yang mampu melakukan kajian untuk menunjang pengembangan keilmuan, serta menghasilkan lulusan yang mempunyai kemandirian dalam mengembangkan keilmuan dan keahliannya bagi masyarakat. Dengan tujuan tersebut menjadi jelas bahwa setiap mahasiswa Program Studi Pendidikan Anak Usia Dini (PG-PAUD) harus memiliki kemampuan dan motivasi untuk mencapai prestasi belajar yang baik serta mencapai tujuan yang diharapkan.

Berdasarkan beberapa pengertian diatas dapat ditarik kesimpulan bahwa motivasi pada dasarnya adalah suatu sugesti atau dorongan yang muncul dari diri seseorang baik secara sadar atau tidak sadar karena dipengaruhi oleh faktor dari dalam diri individu maupun faktor dari luar diri individu untuk melakukan suatu tindakan agar mencapai tujuan yang diharapkan. Beberapa tahun terahir ini banyaknya guru-guru PAUD melanjutkan kuliah S1 (strata satu) pada Program Studi Pendidikan AUD (Anak Usia Dini). Terlebih sebagian besar dari mereka sudah berusia antara 25-30-an tahun, namun mereka memiliki semangat untuk melanjutkan pendidikan/kuliah. Dalam hal ini menjadi hal yang menarik bagi peneliti (state of the art) pastinya banyak faktor yang memotivasi para guru sehingga mereka berkenan melanjutkan pendidikan/kuliah.

Sedangkan dalam penelitian ini, peneliti meyakini bahwa setiap guru memiliki motivasi sendiri-sendiri untuk dapat masuk ke S1 Program Studi Pendidikan Anak Usia Dini (PG-PAUD). Sehingga mendasar pada permasalahan tersebut diatas, maka peneliti tertarik untuk mengetahui dan menganilisis hal-hal yang memotivasi guru-guru dalam melanjutkan S1 Program Studi Pendidikan Anak Usia Dini (PG-PAUD) di Kabupaten Kebumen. 
P-ISSN 2580 - 7781

E-ISSN $2615-3238$

\section{METODE PENELITIAN}

Metode yang digunakan oleh peneliti adalah metode penelitian deskriptif kualitatif. Metode penelitian deskriptif ini bertujuan untuk menjelaskan suatu kejadian. Sedangkan, desain penelitian deskriptif lebih condong pada metode penggunaannya, dimana penelitian deskriptif ini merupakan proses panjang untuk mengumpulkan fakta harus sesuai dengan interpretasi data-data yang tepat. Dalam penelitian ini peneliti mempergunakan data penelitian yang diambil dari kegiatan, aktivitas, hubungan, serta dampak yang ada dalam masyarakat. Langkah-langkah pengembangan rancangan penelitian deskriptif meliputi mengidentifikasi dan memilih masalah yang akan diteliti, merumuskan masalah, melakukan kajian pustaka, menentukan populasi dan sampel, teknik sampling, menentukan instrumen, teknik pengumpulan data, analisis data dan menarik kesimpulan.

Langkah-langkah penelitian ini penulis gambarkan pada gambar berikut:

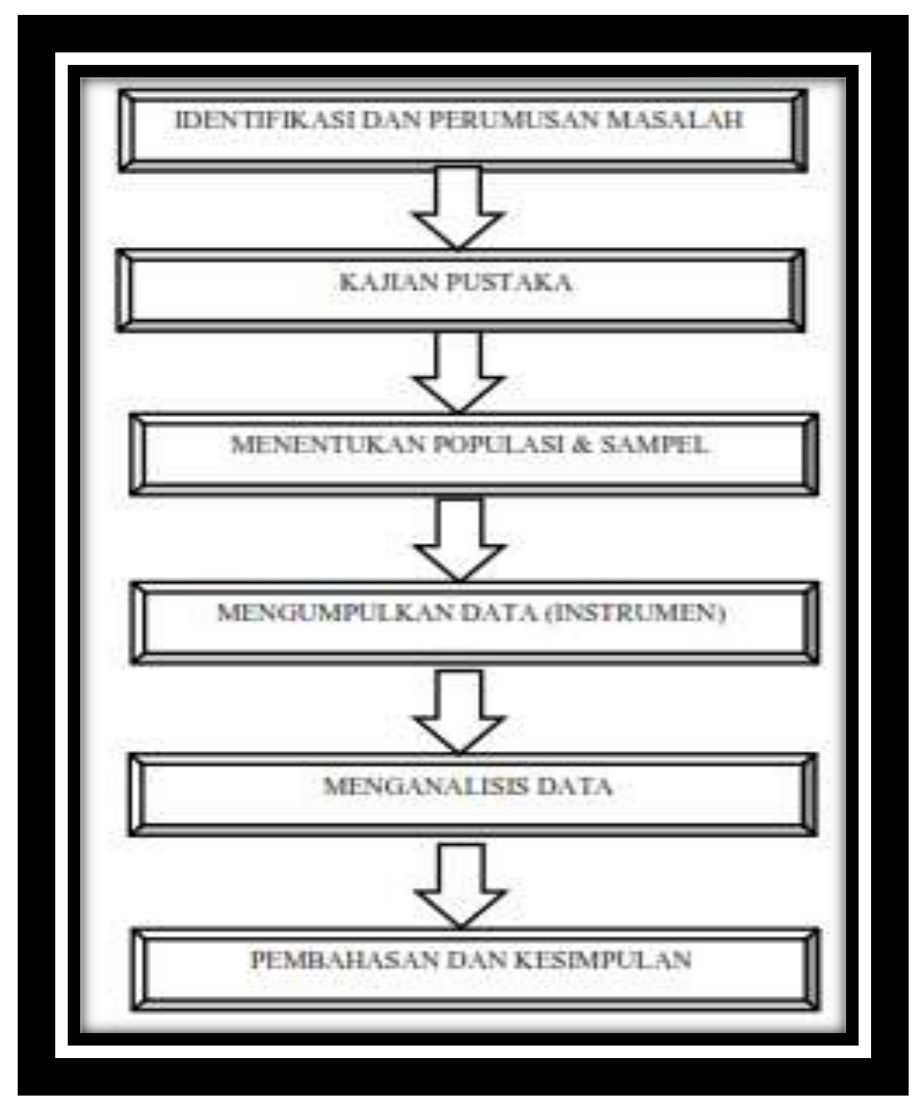


Gambar 1. Tahapan Penelitian

Subjek penelitian nantinya adalah guru-guru yang mengikuti perkuliahan di Program Studi S1 PG-PAUD yang mana data diperoleh melalui bagian kepegawaian Dinas Pendidikan (DISDIK) Kabupaten Kebumen dan data yang ada di Prodi PAUD UMNU Kebumen. Dimana data guru PAUD yang mengambil kuliah S1 ada 197 orang. Peneliti mengambil sampel sebanyak 25 orang dengan teknik random sampling. Teknik Pengumpulan Data pada penelitian ini untuk memperoleh data yang obyektif, Peneliti menggunakan teknik pengumpulan data diantaranya adalah wawancara, observasi dan studi dokumentasi. Analisis data dilakukan sepanjang penelitian dilaksanakan dan mengacu pada model analisis data diskriptif kualitatif terdiri atas tiga alur, yakni: reduksi data, penyajian data, dan penarikan kesimpulan.

\section{HASIL PENELITIAN DAN PEMBAHASAN}

Mendasar pada rencana peneliti terkait tahapan pelaksanaan penelitian sebagaimana yang telah dituangkan pada proposal penelitian sebelumnya. Populasi pada penelitian ini adalah seluruh guru PAUD se-Kabupaten Kebumen yang sudah mengajar pada suatu instansi pendidikan tingkat PAUD. Seperti diketahui bahwa kurang lebih 50\% guru PAUD (KB dan TK) di Kebumen masih berpendidikan SLTA yaitu sekitar 1.277 guru. Sedangkan sampel responden pada penelitian ini yaitu 20 orang dari berbagai instansi PAUD yang tersebar pada setiap kecamatan di Kebumen. Dimana 20 guru tersebut sudah mengajar di sebuah instansi PAUD dan sedang menyelesaikan kuliah S1 Program Pendidikan Anak Usia Dini.

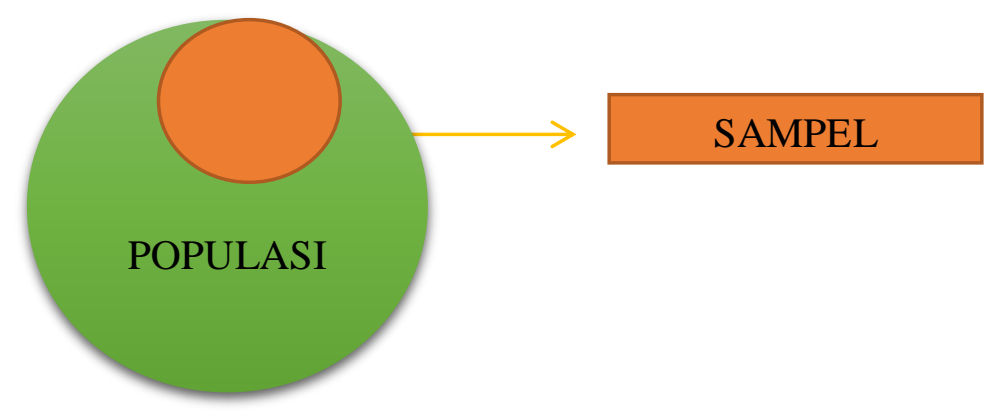


Gambar 2. Skema Populasi dan Sampel Penelitian

Setelah tim peneliti menentukan sampel penelitian, selanjutnya melakukan pengumpulan data (collecting data) dengan metode yang telah direncanakan dan menerapkan protokol kesehatan mengingat pada masa ini awal pandemi Covid 19 mulai merebak, bahkan tim juga melakukan wawancara dengan 2 model yaitu daring (dalam jaringan) dan luar jaringan (luar jaringan). Sedangkan tahapan wawancara adalah sebagai berikut:

\section{Wawancara}

Pada sesi ini, pelaksanaan wawancara peneliti dibagi menjadi 2 kelompok yaitu ketua dan anggota peneliti. Dimana wawancara yang telah dilaksanakan secara luring (luar jaringan) yaitu dengan tatap muka langsung dengan mengajukan 10 pertanyaan kepada mahasiswa sebagai data primer dan 7 pertanyaan kepada dosen PAUD dan 5 pertanyaan kepada Kaprodi PAUD sebagai data sekunder.

2. Observasi

Pada sesi ini, tim peneliti melakukan observasi langsung pada stake holder terkait dengan beberapa pertemuan saja, mengingat era Covid 19 sehingga pertemuan tatap muka sangat terbatas. Observasi pada stake holder yang dimaksud adalah (mahasiswa, Dinas pendidikan, Kaprodi PAUD dan dosen PAUD).

\section{Studi Dokumentasi}

Pada sesi ini, peneliti bersama anggota dan dibantu oleh tim teknis melakukan pengumpulan data, olah data dan analisis data yang selanjutnya melakukan penarikan kesimpulan akhir pada penelitian ini.

Beberapa hasil penelitian menunjukkan hal-hal sebagai berikut:

1. Mendapatkan gambaran/diskripsi motivasi dan perilaku para guru PAUD yang sudah mengajar dan mau melanjutkan kuliah S1 pada Program PAUD.

Gambaran secara umum bahwa mahasiswa Prodi PAUD di Kabupaten Kebumen sudah mengajar di instansi/lembaga masing-masing. Gambaran secara umum bahwa mahasiswa Prodi PAUD di Kabupaten Kebumen sudah mengajar di instansi/lembaga masing-masing, sebagian besar dari mereka berpendidikan SLTA dan rata-rata berusia 30 tahun ke atas. Namun demikian 
mereka memiliki motivasi yang tinggi dalam melanjutkan studi/kuliah S1. Menurut data yang didapat pada sumber Data Guru Kab. Kebumen Dapodikdasmen/ (https://dapo.dikdasmen.kemdikbud.go.id/) adalah dari 1.277 guru PAUD (KB dan TK).

Tabel. 1 Data Guru PAUD (KB dan TK)

\begin{tabular}{|c|c|c|c|c|c|c|c|}
\hline \multirow[b]{2}{*}{ No } & \multirow[b]{2}{*}{ Wilayah } & \multirow{2}{*}{ Jml } & \multicolumn{2}{|c|}{ TK } & \multirow{2}{*}{ Jml } & \multicolumn{2}{|c|}{$\overline{\mathrm{KB}}$} \\
\hline & & & $\mathbf{L}$ & $\mathbf{P}$ & & $\mathbf{L}$ & $\mathbf{P}$ \\
\hline 1 & Kec. Kebumen & 136 & 1 & 135 & 44 & 1 & 43 \\
\hline 2 & Kec. Gombong & 42 & 0 & 42 & 22 & 0 & 22 \\
\hline 3 & Kec. Karanganyar & 31 & 0 & 31 & 17 & 0 & 17 \\
\hline 4 & Kec. Kutowinangun & 43 & 0 & 43 & 6 & 0 & 6 \\
\hline 5 & Kec. Sempor & 71 & 0 & 71 & 9 & 0 & 9 \\
\hline 6 & Kec. Ambal & 41 & 0 & 41 & 13 & 0 & 13 \\
\hline 7 & Kec. Klirong & 46 & 0 & 46 & 14 & 0 & 14 \\
\hline 8 & Kec. Puring & 50 & 1 & 49 & 10 & 0 & 10 \\
\hline 9 & Kec. Alian & 36 & 0 & 36 & 9 & 0 & 9 \\
\hline 10 & Kec. Karanggayam & 29 & 0 & 29 & 9 & 0 & 9 \\
\hline 11 & Kec. Petanahan & 48 & 0 & 48 & 33 & 0 & 33 \\
\hline 12 & Kec. Ayah & 43 & 0 & 43 & 9 & 0 & 9 \\
\hline 13 & Kec. Mirit & 41 & 1 & 40 & 7 & 0 & 7 \\
\hline 14 & Kec. Buluspesantren & 38 & 0 & 38 & 9 & 0 & 9 \\
\hline 15 & Kec. Pejagoan & 29 & 0 & 29 & 14 & 0 & 14 \\
\hline 16 & Kec. Prembun & 23 & 0 & 23 & 3 & 0 & 3 \\
\hline 17 & Kec. Buayan & 36 & 0 & 36 & 9 & 0 & 9 \\
\hline 18 & Kec. Sruweng & 28 & 0 & 28 & 7 & 0 & 7 \\
\hline 19 & Kec. Rowokele & 13 & 0 & 13 & 7 & 0 & 7 \\
\hline 20 & Kec. Kuwarasan & 39 & 1 & 38 & 5 & 1 & 4 \\
\hline 21 & Kec. Adimulyo & 29 & 0 & 29 & 10 & 0 & 10 \\
\hline 22 & Kec. Karangsambung & 19 & 0 & 19 & 7 & 0 & 7 \\
\hline 23 & Kec. Bonorowo & 26 & 1 & 25 & 9 & 0 & 9 \\
\hline 24 & Kec. Poncowarno & 12 & 0 & 12 & 3 & 0 & 3 \\
\hline 25 & Kec. Sadang & 16 & 0 & 16 & 8 & 0 & 8 \\
\hline 26 & Kec. Padureso & 14 & 0 & 14 & 5 & 0 & 5 \\
\hline Total & Total & 979 & 5 & 974 & 298 & 2 & 296 \\
\hline
\end{tabular}

2. Menggali informasi terkait hubungan antara motivasi kuliah guru PAUD dengan kendala/tanggung jawab mereka menjadi seorang mahasiswa. Sebagaimana pengertian motivasi menurut Mc Donald yang dikutip Wasty Soemanto bahwa motivasi sebagai perubahan tenaga di dalam diri seseorang 
yang ditandai oleh dorongan efektif dan reaksi-reaksi mencapai tujuan (Soemanto, 1998). Selanjutnya motivasi juga berfungsi sebagai pendorong usaha dan pencapaian prestasi. Dengan adanya usaha yang tekun dan terutama didasari adanya motivasi, maka seseorang yang belajar itu akan dapat melahirkan prestasi yang baik. (Sulistyawati, 2015). Hasil analisis dan olah data pada penelitian ini menunjukkan bahwa beberapa motivasi guru PAUD dalam memutuskan untuk lanjut kuliah secara dominasi terbanyak urutan teratas adalah sebagai berikut:

a. Menambah wawasan dan keilmuan.

b. Harapan peningkatan kesejahteraan melalui program sergur (sertifikasi pendidik guru).

c. Jarak tempuh yang dekat, sehingga akses, komunikasi dan koordinasi dapat dilakukan dengan efektif dan efisien.

d. Motivasi dari pihak luar (keluarga dan kerabat).

e. Perguruan tinggi tempat kuliah memiliki sistem perkuliahan yang mudah dan biaya yang terjangkau.

3. Mendiskripsikan dampak dan pengaruh yang muncul dimasyarakat terkait motivasi guru-guru PAUD dalam melanjutkan kuliah S1 PG-PAUD. Dalam kaitannya hal ini, peneliti menangkap hal-hal positif yang muncul;

a. Beberapa mahasiswa termotivasi dalam melanjutkan kuliah dikarenakan melihat rekan sejawat yang melanjutkan kuliah.

b. Kesibukan seorang ibu dan guru sekaligus menjadi seorang mahasiswi dapat diselesaikan bersama ketika seseorang dapat mengatur waktu dan mengatur skala prioritas dengan baik.

c. Untuk melanjutkan kuliah/studi lanjut tidak harus menghabiskan biaya yang banyak.

d. Untuk warga Kebumen khususnya, bahwa kuliah tidak perlu jauh karena sudah terlayani di Kabupaten sendiri karena ada 2 (dua) Perguruan Tinggi yang membuka Prodi PG-PAUD yaitu (UT dan UMNU) Kebumen.

e. Ada stigma bahwa usia tidaklah menjadi penghalang bagi seseorang untuk menuntut ilmu. 
P-ISSN 2580 - 7781

E-ISSN $2615-3238$

\section{KESIMPULAN}

Mendasar pada hasil dan pembahasan penelitian ini muncul beberapa kesimpulan yang menjadi dominasi motivasi guru-guru untuk melanjutkan belajar/kuliah S1 PAUD antara lain adalah bahwa menambah wawasan keilmuan. Wawasan keilmuan yang dimaksud berupa akademik dan non akademik yang diperoleh selama kuliah. Dalam hal ini mereka berharap dengan melanjutkan kuliah maka akan meningkatkan wawasan dan keilmuan mereka yang lebih luas. Keilmuan akademik diperoleh selama mereka melaksanakan perkuliahan secara normatif. Kemudian wawasan non akademik dapat diperoleh diluar bangku kuliah diantaranya dengan mereka mengikuti organisasi dan saling mengenal satu sama lain yang berasal dari berbagai Lembaga PAUD masing-masing. Selanjutnya, motivasi guru PAUD dalam memutuskan untuk lanjut kuliah adalah adanya harapan peningkatan kesejahteraan setelah mendapatkan gelar sarjana. Dalam hal ini bahwa secara regulasi terkait guru PAUD baik regulasi yang berasal dari PEMDA ataupun Kementerian Pendidikan bahwa untuk mendapatkan kesra (kesejahteraan) dan sertifikasi guru maka harus berpendidikan minimal S1 sedangkan sebagian besar guru PAUD di Kebumen masih berpendidikan SLTA sederajat.

\section{DAFTAR PUSTAKA}

Miles, M. B. dan Huberman, A. M. 1992. AnalisisData Kualitatif. Jakarta. Universitas Indonesia Press.

Nasution, S. 1988. Metode Penelitian Naturalistik Kualitatif. Bandung: Tarsito

Soemanto, W. 1998. Psikologi Pendidikan, Jakarta: RinekaCipta.

Sulistyawati, H. 2015. Hubungan Antara Motivasi Menjadi Bidan dengan Prestasi Belajar Asuhan Kebidanan Ibu Hamil pada Mahasiswa Semester II Prodi DIII Kebidanan (Studi di Stikes Icme Jombang). Jurnal Insan Cendekia. Vol. 2 No. 1. 